\title{
Management of Patients with Asymptomatic Carotid Stenosis May Need to Be Individualized: A Multidisciplinary Call for Action
}

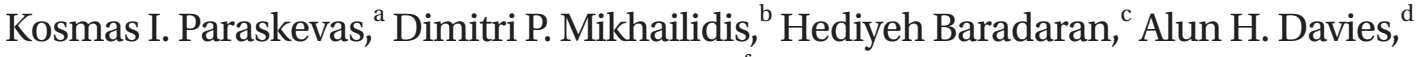 \\ Hans-Henning Eckstein, ${ }^{\mathrm{e}}$ Gianluca Faggioli, ${ }^{\mathrm{f}}$ Jose Fernandes e Fernandes, ${ }^{\mathrm{g}}$ Ajay Gupta, ${ }^{\mathrm{h}}$ \\ Mateja K. Jezovnik, ${ }^{\mathrm{i}}$ Stavros K. Kakkos, ${ }^{j}$ Niki Katsiki, ${ }^{\mathrm{k}}$ M. Eline Kooi, ${ }^{1, \mathrm{~m}}$ Gaetano Lanza, ${ }^{\mathrm{n}}$ \\ Christos D. Liapis, ${ }^{\circ}$ Ian M. Loftus, ${ }^{\mathrm{p}}$ Antoine Millon, ${ }^{\mathrm{q}}$ Andrew N. Nicolaides, ${ }^{\mathrm{r}}$ Pavel Poredos, ${ }^{\mathrm{s}}$ \\ Rodolfo Pini, ${ }^{\mathrm{f}}$ Jean-Baptiste Ricco, ${ }^{\mathrm{t}}$ Tatjana Rundek, ${ }^{\mathrm{u}}$ Luca Saba, ${ }^{\mathrm{v}}$ Francesco Spinelli, ${ }^{\mathrm{w}}$ Francesco Stilo, ${ }^{\mathrm{w}}$ \\ Sherif Sultan, ${ }^{\mathrm{x}}$ Clark J. Zeebregts, ${ }^{\mathrm{y}}$ Seemant Chaturvedi ${ }^{\mathrm{z}}$ \\ aDepartment of Vascular Surgery, Central Clinic of Athens, Athens, Greece \\ bDepartment of Clinical Biochemistry, Royal Free Hospital Campus, University College London Medical School, University College London (UCL), London, UK \\ 'Department of Radiology, University of Utah, Salt Lake City, UT, USA \\ dSection of Vascular Surgery, Imperial College \& Imperial Healthcare NHS Trust, London, UK \\ eDepartment of Vascular and Endovascular Surgery, Klinikum rechts der Isar, Technical University of Munich, Munich, Germany \\ fVascular Surgery, University of Bologna "Alma Mater Studiorum", Policlinico S. Orsola Malpighi, Bologna, Italy \\ ${ }^{9}$ Department of Vascular Surgery, University of Lisbon, Lisbon Academic Medical Center, Lisbon, Portugal \\ hDepartment of Radiology, Weill Cornell Medicine, New York, NY, USA \\ 'Department of Advanced Cardiopulmonary Therapies and Transplantation, The University of Texas Health Science Centre at Houston, Houston, TX, USA \\ 'Department of Vascular Surgery, University of Patras Medical School, Patras, Greece \\ kFirst Department of Internal Medicine, AHEPA University Hospital, Thessaloniki, Greece \\ 'CARIM School for Cardiovascular Diseases, Maastricht University, Maastricht, The Netherlands \\ ${ }^{m}$ Department of Radiology and Nuclear Medicine, Maastricht University Medical Center, Maastricht, The Netherlands \\ "Vascular Surgery Department, IRCSS MultiMedica Hospital, Castellanza, Italy \\ ${ }^{\circ}$ Athens Vascular Research Center, Athens, Greece

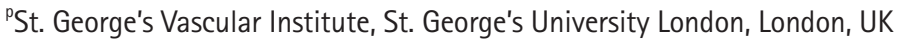 \\ ${ }^{9}$ Department of Vascular and Endovascular Surgery, Louis Pradel Hospital, Hospices Civils de Lyon, France \\ 'Department of Surgery, University of Nicosia Medical School, Nicosia, Cyprus \\ ${ }^{\text {s} D e p a r t m e n t ~ o f ~ V a s c u l a r ~ D i s e a s e, ~ U n i v e r s i t y ~ M e d i c a l ~ C e n t r e ~ L j u b l j a n a, ~ S l o v e n i a ~}$ \\ tDepartment of Clinical Research, University of Poitiers, CHU de Poitiers, Poitiers, France \\ "Department of Neurology, Miller School of Medicine, University of Miami, Miami, FL, USA \\ 'Department of Radiology, Azienda Ospedaliera Universitaria Di Cagliari, Cagliari, Italy \\ "Vascular Surgery Division, Campus Bio-Medico University of Rome, Rome, Italy \\ "Western Vascular Institute, Department of Vascular and Endovascular Surgery, University Hospital Galway, National University of Ireland, Galway, Ireland \\ 'Division of Vascular Surgery, Department of Surgery, University Medical Center Groningen, University of Groningen, Groningen, The Netherlands \\ zDepartment of Neurology \& Stroke Program, University of Maryland School of Medicine, Baltimore, MD, USA
}

The optimal management of patients with asymptomatic carotid stenosis (ACS) is the subject of extensive debate. According to the 2017 European Society for Vascular Surgery guidelines, carotid endarterectomy should (Class Ila; Level of Evidence: B) or carotid artery stenting may be considered (Class Ilb; Level of Evidence: B) in the presence of one or more clinical/imaging characteristics that may be associated with an increased risk of late ipsilateral stroke (e.g., silent embolic infarcts on brain computed tomography/magnetic resonance imaging, progression in the severity of ACS, a
Correspondence: Kosmas I.

Paraskevas

Department of Vascular Surgery,

Central Clinic of Athens, 24

Alexander Papagou Street, N. Iraklio

14122 , Athens, Greece

Tel: +30-698-3133883

Fax: +30-210-3215792 
history of contralateral transient ischemic attack/stroke, microemboli detection on transcranial Doppler, etc.), provided documented perioperative stroke/death rates are $<3 \%$ and the patient's life expectancy is $>5$ years. Besides these clinical/imaging characteristics, there are additional individual, ethnic/racial or social factors that should probably be evaluated in the decision process regarding the optimal management of these patients, such as individual patient needs/patient choice, patient compliance with best medical treatment, patient sex, culture, race/ethnicity, age and comorbidities, as well as improvements in imaging/operative techniques/outcomes. The present multispecialty position paper will present the rationale why the management of patients with ACS may need to be individualized.

Keywords Endarterectomy, carotid; Carotid stenosis; Stroke; Ischemic attack, transient; Life expectancy; Patient preference
E-mail: paraskevask@hotmail.com https://orcid.org/0000-0001-68652919

Received: October 15, 2020

Revised: February 21, 2021

Accepted: April 12, 2021

\section{Introduction}

The optimal management of patients with asymptomatic carotid stenosis (ACS) is a controversial and much debated issue. According to the 2020 Heart Disease and Stroke Statistics, each year around 800,000 Americans experience a new or recurrent stroke. 'Of these, about 600,000 are first strokes, while the rest are recurrent episodes. ${ }^{1}$ Projections show that by 2030, an additional 3.4 million United States adults will have suffered a stroke, representing a $20.5 \%$ increase in the prevalence from $2012 .^{1}$

The global prevalence of ischemic stroke in 2017 was 82.4 million; that is, a 16.1\% increase from 2007 to 2017 and a $10.1 \%$ increase from 1990 to 2017 . $^{1}$ Furthermore, a total of 2.7 million individuals died globally of ischemic stroke in 2017.' In Europe, there are approximately 1.4 million strokes/year causing about 1.1 million deaths annually. ${ }^{2}$ Around $10 \%$ to $15 \%$ of those strokes occur as a result of thromboembolism from a previously asymptomatic significant carotid stenosis. ${ }^{2,3}$

Medical treatment has improved considerably in the last 10 to 15 years. ${ }^{4}$ It was thus supported that the annual risk of stroke while on current best medical treatment (BMT) alone may be declining compared with the randomized controlled trials (RCTs) performed 20 to 30 years ago. ${ }^{2}$ Consequently, it was proposed that there is a need to develop clinical/imaging algorithms for identifying a smaller, but higher-risk for stroke cohort in whom carotid endarterectomy (CEA)/carotid artery stenting (CAS) might be targeted. ${ }^{2,5}$ The 2017 European Society for Vascular Surgery (ESVS) guidelines for the management of patients with carotid artery stenosis recommended that in "average surgical risk" patients with a 60\% to 99\% ACS, CEA should (Class lla; Level of Evidence: B) or CAS may be considered (Class Ilb; Level of Evidence: B) in the presence of one or more clinical/imaging characteristics that may be associated with an increased risk of late ipsilateral stroke, provided documented perioperative stroke/death rates are $<3 \%$ and patient life expectancy is $>5$ years. ${ }^{2}$ These clinical/imaging characteristics included silent embolic infarcts on brain computed tomography (CT)/magnetic resonance imaging (MRI), progression in the severity of ACS, a history of contralateral transient ischemic attack/stroke, microemboli detection on transcranial Doppler, the presence of intraplaque hemorrhage or plaque ulceration on $\mathrm{MRI}$, reduced cerebrovascular reserve, a large plaque area $\left(>40 \mathrm{~mm}^{2}\right)$ on ultrasound longitudinal images and plaque echolucency as shown by a low gray scale median $(<30)$ and presence of a large $(>8$ $\mathrm{mm}^{2}$ ) juxtaluminal hypoechoic area after image normalization of Duplex ultrasound images. ${ }^{2,5-7}$

Besides these clinical/imaging characteristics, there are additional individual, ethnic/racial, cultural or social factors that should probably be evaluated in the decision process regarding the optimal management of these patients. The current position statement considers the evidence why the optimal management of patients with ACS may occasionally need to be individualized.

\section{Individual characteristics to consider}

Some factors/characteristics that may prompt physicians to consider individualization of the management of ACS in specific patients include.

\section{Individual patient needs/patient choice}

Not all patients have the same lifestyle and social/cultural background. Some patients are more active, others live more sedentary lives. The management of patients with different lifestyles should be tailored to their individual needs. In addition, patients have different characters and attitudes towards their disease; individual perception and emotional attitude are im- 
portant parameters. ${ }^{8}$ For some patients it may be quite stressful knowing that they have a high-grade ACS, which may lead to a stroke. In contrast, others may not wish to undergo a surgical procedure. 8 Such individual factors, surroundings and attitudes should be taken into account when discussing the management of ACS with each patient. Patients have the right to choose if they want to undergo a procedure and accept the perioperative risk associated with $\mathrm{CEA} / \mathrm{CAS}$, or instead be managed by BMT alone.

Traditional models where all treatment decisions are made by the health professionals are no longer desired by patients and their families. ${ }^{9}$ Patients want to be active participants in decision-making regarding their health and treatment choices. ${ }^{9} \mathrm{~A}$ survey from the UK a few years ago regarding the management of a unilateral $70 \%$ ACS revealed that $48 \%$ of the study participants would opt for BMT alone whereas 52\% preferred an intervention (30\% CEA; 22\% CAS). ${ }^{10}$ The most common reasons for choosing BMT over an intervention were avoidance of surgery and the risk of periprocedural stroke/death.

A subgroup analysis by gender demonstrated that $43 \%$ of men and $60 \%$ of women opted for BMT. ${ }^{10}$ Another $35 \%$ of men and $20 \%$ of women selected CEA, while CAS was preferred by $22 \%$ of men and $20 \%$ of women. ${ }^{10}$ A subgroup analysis by age revealed that BMT was preferred by $39 \%$ of patients aged $<70$ years versus $55 \%$ for those $\geq 70$ years, whereas CEA by $35 \%$ ( $<70$ years) versus $27 \%$ ( $\geq 70$ years) and CAS by $26 \%$ ( $<70$ years) versus $18 \%$ ( $\geq 70$ years), respectively. Patients with a first-degree relative who had suffered a stroke were equally likely to choose an intervention compared with individuals who did not have a similar history (52\% vs. 53\%, respectively). ${ }^{10}$ Furthermore, a larger proportion of patients who had suffered a contralateral event chose BMT compared with those who had never had a stroke or transient ischemic attack (64\% vs. 47\%). Active smokers expressed a modest preference for CEA (8/21, 38\%) over BMT $(7 / 21,33 \%)$ or CAS $(6 / 21,29 \%)$, while ex- and non-smokers preferred BMT $(42 / 81,52 \%)$ over CEA $(23 / 81,28 \%)$ or CAS $(16 / 81,20 \%) . .^{10}$ Overall, the group most likely to opt for an open/ endovascular intervention was male smokers under 70 years of age. $^{10}$

Avoidance of surgery and the associated periprocedural risk may be valid reasons to choose BMT over CEA/CAS. ${ }^{10}$ On the other hand, the lower stroke/death rates associated with CEA compared with CAS may play a pivotal role for some patients when selecting an intervention. By contrast, others opt for the less invasive CAS over CEA, placing more emphasis on the scar size, a previous positive experience with arterial stenting elsewhere (e.g., in the lower limb arteries) and the lower cranial nerve injury rates. ${ }^{10}$ Thus, individual ACS patients may opt for different treatment options using a variety of criteria.

\section{Individual patient culture/ethnicity/race}

The decision to undergo CEA may vary by ethnicity/race. Black patients may have higher aversion scores to CEA compared with white individuals. ${ }^{11}$ One of the reasons that might influence this decision to avoid CEA may be the fact that CEA does not relieve pain or prolong life, but is performed to reduce the risk of future stroke. ${ }^{11}$ According to the authors, ${ }^{11}$ the "risk of future stroke" may be a difficult concept to explain to some individuals.

A large study ( $n=890,680$ patients undergoing CEA/CAS; 92.1\% for ACS) identified ethnic/racial and financial disparities in the decision to be offered CEA for ACS. ${ }^{12}$ Compared with white ACS patients, black (odds ratio [OR], 0.72; 95\% confidence interval [Cl], 0.69 to $0.75 ; P<0.0001)$, Hispanic $(0 R, 0.79$; $95 \% \mathrm{Cl}, 0.76$ to $0.82 ; P<0.0001)$, and Asian patients (OR, 0.81; $95 \% \mathrm{Cl}, 0.76$ to $0.82 ; P<0.0001)$ were less likely to be offered a carotid revascularization procedure for ACS. ${ }^{12}$ When adjusted for age ( $<65$ years vs. $\geq 65$ years), black $(O R, 0.73 ; 95 \% \mathrm{Cl}, 0.69$ to $0.78 ; P<0.0001)$, and Hispanic ACS patients (OR, 0.79; 95\% $\mathrm{Cl}, 0.74$ to 0.85 ; $P<0.0001$ ) were less likely to be offered a revascularization procedure compared with white ACS patients $<65$ years, whereas Asian patients did not differ significantly (OR, 0.91; 95\% Cl, 0.78 to $1.06 ; P>0.05)$. In contrast, for those $\geq 65$ years, black $(0 \mathrm{R}, 0.74 ; 95 \% \mathrm{Cl}, 0.71$ to $0.78 ; P<0.0001)$, Hispanic $(\mathrm{OR}, 0.79 ; 95 \% \mathrm{Cl}, 0.76$ to $0.83 ; P<0.0001)$, and Asian patients $(0 \mathrm{R}, 0.77 ; 95 \% \mathrm{Cl}, 0.70$ to $0.84 ; P<0.0001)$ were all less likely to be offered a carotid revascularization procedure for ACS compared with white individuals. Finally, Medicaid (OR, $0.60 ; 95 \% \mathrm{Cl}, 0.58$ to $0.64 ; P<0.0001)$, private insurance $(0 \mathrm{R}$, $0.78 ; 95 \% \mathrm{Cl}, 0.77$ to $0.79 ; P<0.0001)$, and self-pay patients $(\mathrm{OR}, 0.37 ; 95 \% \mathrm{Cl}, 0.28$ to $0.46 ; P<0.0001)$ were less likely to be offered CEA for ACS compared with Medicare individuals. ${ }^{12}$

Minority patients and individuals of lower socioeconomic status have generally less access to medical care for the treatment of vascular risk factors. An analysis of data from the National Health and Nutrition Examination Surveys demonstrated that Hispanic and black patients were significantly less likely to have adequate control of hypertension and hypercholesterolemia compared with white patients. ${ }^{13}$ Another study demonstrated that black patients were less likely to be aware of and controlled/treated for dyslipidemia compared with white patients. ${ }^{14}$ Finally, a report from the Center for Disease Control and Prevention showed that black patients not only had higher rates of hypertension compared with white patients, but they were also less likely to have blood pressure control. ${ }^{15}$

Besides the factors associated with a patient's likelihood to be offered CEA or his/her decision to undergo CEA (which 
may vary according to ethnic criteria/beliefs), another parameter which may affect individual decision-making is that CEA outcomes may vary by ethnicity/race. In the New York Carotid Artery Surgery Study ( $n=9,308$ CEA procedures), individuals of Hispanic-Latino ethnicity undergoing CEA had considerably higher death and stroke rates compared with non-Hispanic black or non-Hispanic white patients $(9.50 \%$ vs. $6.93 \%$ vs. $3.80 \%$, respectively; $P<0.0001) .{ }^{16}$ Possible explanations for these disparities in outcomes according to patient ethnicity include increased comorbidities preoperatively, poor patient selection, confounding by socioeconomic status and other non-medical factors including increased proportion of non-white patients offered CEA at low-volume institutions by less experienced surgeons. ${ }^{16-20}$ Chaturvedi et al. ${ }^{20}$ demonstrated that black ACS patients receiving CEA in two urban hospitals tended to have higher stroke or myocardial infarction (MI) rates compared with white individuals ( $15.4 \%$ vs. $5.6 \%, P=0.065$ ). In black patients who received surgery in the hospital with the lowest CEA volume, stroke or MI rates were significantly higher $(20.5 \%$, $P<0.05)$ compared with white patients. ${ }^{20}$ The reasons for these unfavorable outcomes after CEA in black ACS patients included a higher prevalence of vascular risk factors (e.g., hypertension, diabetes, and smoking) and more women treated with CEA. ${ }^{20}$ Consequently, the association between individual ethnic parameters with CEA outcomes may affect the type of treatment selected by patients or offered by physicians.

\section{Patient age/comorbidities}

As active and well-informed participants by health professionals, patients can make their own decision about whether to undergo a prophylactic CEA. Age and comorbidities may play a key role in their decision-making (Table 1). ${ }^{16,21-27}$ According to national statistics, the 5-year mortality of individuals aged 80 to 85 years is nearly $30.0 \%$ and it is higher in males than in females ( $40.6 \%$ vs. $23.4 \%$, respectively; $P<0.0001) .{ }^{21}$ Due to the high non-stroke-related mortality in this age group (e.g., due to cancer, respiratory causes, etc.), the net benefit of a prophylactic CEA in such elderly patients is debatable. ${ }^{21,28}$ Furthermore, octogenarians and nonagenarians have been excluded from past RCTs; consequently, the number needed to treat to prevent one stroke in elderly ACS patients is unknown. ${ }^{28,29}$ The need to be cautious when offering a carotid intervention to elderly patients was underlined by some authors. ${ }^{22,23}$ Appropriate and rigorous patient selection for a carotid intervention is mandatory, especially in such a fragile population. ${ }^{24}$

Patients with multiple comorbidities have a high risk not only of surgical/periprocedural complications, but also of future stroke. A large study collected data from the National Surgi- cal Quality Improvement Program (NSOIP) about preoperative risk factors for all patients undergoing CEA from 2005 to 2011 ( $n=44,832 ; 27,136$ ACS patients). ${ }^{30}$ A frailty Risk Analysis Index (RAl) score was developed using various comorbidities (e.g., malignant disease, congestive heart failure, shortness of breath at rest, renal insufficiency, etc.) and social parameters (e.g., functional status, type of residency [home, assisted living, nursing home], etc)..$^{30} \mathrm{~A}$ linear correlation was demonstrated in ACS patients undergoing CEA between increasing frailty RAl score with perioperative risk of stroke. Perioperative stroke/death rates increased with increasing frailty RAl score, at some point reaching and exceeding the perioperative stroke/death threshold of $3 \%{ }^{30}$

In another more recent (2005 to 2012) analysis of the NSOIP data, frailty was strongly associated with morbidity and mortality among patients undergoing CEA, but not $\mathrm{CAS}^{31}{ }^{31}$ Among 37,875 patients undergoing a carotid intervention, frailty was an independent predictor of complications (23.5\% vs. $7.2 \%$, respectively; $P<0.001)$, mortality $(5.2 \%$ vs. $1.1 \%$, respectively; $P=0.02)$, failure to rescue ( $12.1 \%$ vs. $4.7 \%$, respectively; $P=0.02)$, and 30 -day readmissions ( $14.9 \%$ vs. $3.7 \%$, respectively; $P=0.03$ ) compared with non-frail patients. Consequently, the potential benefits of offering an intervention (CEA/CAS) plus BMT versus BMT alone in elderly ACS patients must be counterbalanced against the potential risks associated with each option.

The value of informed consent is crucial. Patients should not be provided data from obsolete trials such as the Asymptomatic Carotid Atherosclerosis Study (ACAS), ${ }^{32}$ but instead should be counseled with the best possible information on outcomes with current BMT and surgical results. The results of an objective assessment of comorbidities by the treating physician (including patient frailty and life-expectancy) should be presented to the patient. ${ }^{9}$ They need to understand the uncertainty, risks and benefits of the management of ACS. ${ }^{9}$ Younger ACS patients with a longer life expectancy may prefer to have a prophylactic CEA, while older ACS patients may choose to avoid CEA/CAS. ${ }^{10}$

In an analysis of the Statutory German Quality Assurance Database on all CEAs performed between 2009 and 2014 ( $n=142,074 ; 85,738$ for ACS), there was a strong association between in-hospital stroke/death rates with age. ${ }^{25}$ Age was associated with a higher risk of any in-hospital stroke/death (relative risk [RR] per 10-year increase, $1.19 ; 95 \% \mathrm{Cl}, 1.14$ to 1.24 ; $P<0.01)$ and a higher risk of death alone $(\mathrm{RR}, 1.68 ; 95 \% \mathrm{Cl}, 1.54$ to $1.84 ; P<0.01)$ in CEA patients. Age was also associated with a higher risk of stroke alone (RR, $1.05 ; 95 \% \mathrm{Cl}, 1.00$ to 1.11 ; $P<0.05)$, but this relationship was weaker. ${ }^{25}$

A study presenting the outcomes after 22,516 CAS procedures $(10,677$ on symptomatic [47.4\%] and 11,839 on ACS patients [52.6\%]) revealed an interesting finding. ${ }^{33}$ ACS patients 
Table 1. Studies reporting outcomes of carotid revascularization procedures in elderly ACS patients

\begin{tabular}{|c|c|c|}
\hline Study & Study aim/study design & Results \\
\hline \multicolumn{3}{|c|}{ Studies comparing different age groups } \\
\hline $\begin{array}{l}\text { Halm et al. }{ }^{16} \\
(2009)\end{array}$ & $\begin{array}{l}\text { Analysis of the results of 9,308 CEAs by age ( }<70 \text { years: } 2,152 \\
\text { CEAs; } 70-79 \text { years: } 4,958 \text { CEAs; } \geq 80 \text { years: } 2,198 \text { CEAs) }\end{array}$ & $\begin{array}{l}\text { Ipsilateral stroke/death rates ( } \geq 80 \text { vs. } 70-79 \text { years): } \\
4.82 \% \text { vs. } 3.73 \% ; P<0.02\end{array}$ \\
\hline $\begin{array}{l}\text { Rajamani et al. } \\
(2013)\end{array}$ & $\begin{array}{l}\text { Comparison of outcomes stratified by age ( }<75 \text { vs. } 75 \text { to }<80 \text { vs. } \\
80 \text { to }<85 \text { vs. }>85 \text { years) among symptomatic }(n=1,376) \text { and } \\
\text { asymptomatic ( } n=2,773) \text { patients undergoing CEA }\end{array}$ & $\begin{array}{l}\text { Overall mortality for patients }<75 \text { vs. }>85 \text { years: } \\
0.1 \% \text { vs. } 1.7 \% ; P=0.002 \\
\text { In-hospital death } / \text { stroke/Ml for patients }<75 \text { vs. }>85 \text { years: } \\
2.2 \% \text { vs. } 5.6 \% ; P=0.003\end{array}$ \\
\hline $\begin{array}{l}\text { Schmid et al. } \\
\text { (2017) }\end{array}$ & $\begin{array}{l}\text { Analysis of } 142,074 \text { CEAs ( } 85,738 \text { for ACS; 56,336 for symptomatic } \\
\text { carotid stenosis) from the Statutory German Quality Assurance } \\
\text { Database between 2009-2014 }\end{array}$ & $\begin{array}{l}\text { Crude risk of any in-hospital stroke/death for ACS patients } \\
\text { aged }<65,65-69,70-74,75-79 \text {, and } \geq 80 \text { years: } \\
1.0 \% \text { vs. } 1.3 \% \text { vs. } 1.3 \% \text { vs. } 1.5 \% \text { vs. } 1.9 \% \text {, respectively } \\
(P<0.001 \text { for trend })\end{array}$ \\
\hline \multicolumn{3}{|c|}{ Studies reporting outcomes in the elderly } \\
\hline $\begin{array}{l}\text { Rinckenbach et al. }{ }^{27} \\
\text { (2007) }\end{array}$ & $\begin{array}{l}\text { Evaluation of outcomes after CEA in } 57 \text { ACS patients } \\
\geq 80 \text { years old }\end{array}$ & $\begin{array}{l}\text { Perioperative ipsilateral stroke/death rate: } 8.8 \% \\
\text { Kaplan-Meier 5-year survival: } 52 \%\end{array}$ \\
\hline $\begin{array}{l}\text { De Rango et al. }{ }^{21} \\
(2012)\end{array}$ & $\begin{array}{l}\text { Assessment of the clinical relevance of carotid revascularization } \\
\text { procedures in patients } \geq 80 \text { years old ( } n=348 \text { procedures in } 323 \\
\text { patients; } 179 \text { ACS patients) }\end{array}$ & $\begin{array}{l}\text { All-cause 5-year mortality: } 65.4 \% \\
\text { All-cause 5-year mortality in ACS patients: } 67.8 \%\end{array}$ \\
\hline $\begin{array}{l}\text { Salomon du Mont et } \\
(2014)\end{array}$ & $\begin{array}{l}\text { Overview of the results of } 132 \text { CEAs in } 118 \text { patients } \geq 80 \text { years } \\
\text { (50 CEAs on symptomatic; } 82 \text { CEAs on ACS patients) }\end{array}$ & Ipsilateral stroke/death rate for ACS patients: 4.88\% \\
\hline $\begin{array}{l}\text { Wach et al. }{ }^{23} \\
(2015)\end{array}$ & $\begin{array}{l}\text { Evaluation of CAS safety and efficacy in patients aged } \geq 90 \text { years } \\
(\mathrm{n}=21 \text { CAS procedures in } 20 \text { patients; } 11 \text { symptomatic; } 9 \text { ACS } \\
\text { patients [10 CAS procedures]) }\end{array}$ & $\begin{array}{l}\text { Perioperative stroke rate for ACS patients: } 10 \% \\
50 \% \text { of ACS patients were alive at } 47 \text { months }\end{array}$ \\
\hline $\begin{array}{l}\text { Hobbs et al. }^{26} \\
(2020)\end{array}$ & Analysis of CEA outcomes offered to 33 ACS patients $\geq 90$ years & $\begin{array}{l}\text { 30-day mortality rate: } 6.1 \% \\
\text { Median survival: } 29.4 \text { months }\end{array}$ \\
\hline
\end{tabular}

ACS, asymptomatic carotid stenosis; CEA, carotid endarterectomy; MI, myocardial infarction; CAS, carotid artery stenting.

offered CAS had periprocedural death, stroke and MI rates of $1.0 \%(95 \% \mathrm{Cl}, 0.9$ to 1.2 ), $2.3 \%(95 \% \mathrm{Cl}, 2.1$ to 2.6 ), and $2.2 \%$ (95\% Cl, 2.0 to 2.5), respectively. Nevertheless, mortality rates during a mean follow-up time of 2 years for ACS patients were as high as $27.7 \%(95 \% \mathrm{Cl}, 26.4$ to 28.9). For ACS patients aged $\geq 80$ years in particular ( $n=7,255$ patients), a staggering mean 2-year mortality of $41.5 \%(95 \% \mathrm{Cl}, 39.7$ to 43.3$)$ was reported. ${ }^{33}$ Therefore, almost half of those ACS patients aged $\geq 80$ years did not live long enough to obtain benefit from CEA in terms of stroke prevention. ${ }^{33}$ Similar results were reported in a more recent single-center study discussing the outcomes of CEA in ACS nonagenarians. ${ }^{26}$ Based on the reported median postoperative survival of 29 months in their group of ACS nonagenarians, the authors advised that the enthusiasm for offering CEA to elderly ACS individuals should be tempered by the low survival rates. ${ }^{26}$ This finding raises some serious concerns about the appropriateness of offering carotid revascularization procedures to very elderly ACS patients.

\section{Patient sex}

A previous analysis of combined results from ACAS $^{11}$ and the Asymptomatic Carotid Surgery Trial (ACST) ${ }^{29}$ revealed that asymptomatic men had a 51\% RR reduction with CEA, whereas there was no clear benefit in women. ${ }^{34}$ Women with ACS tend to be older and their perioperative outcomes are worse. ${ }^{34}$ Elderly ACS women in particular have high mortality rates due to ischemic stroke (up to $40.0 \%$ at 5 years), which prevents a net benefit from carotid revascularization. ${ }^{21}$

Consequently, not only are older women at higher perioperative stroke/death risk after CEA, but they are also more likely to experience more severe strokes and higher stroke disability. According to the 2020 United States Heart Disease and Stroke Statistics, each year approximately 55,000 more females than males suffer a stroke. ${ }^{1}$ Sex-specific stroke rates in some areas have declined significantly since 1993 for males, but not for females. ${ }^{35}$ This trend was seen for all-strokes and ischemic strokes, but not for hemorrhagic strokes. ${ }^{35}$

In addition, studies evaluating carotid plaques in women who have undergone CEA demonstrated more smooth muscle cells and a smaller degree of macrophage infiltration, suggesting a more stable phenotype. ${ }^{36}$ Clinicians also need to consider competing risks of stroke. Elderly women, in particular, are more likely to have an ischemic stroke due to atrial fibrillation rather than ACS. ${ }^{37}$

An in vivo 3.0-T MRI study of carotid plaque features attempted to explain the sex differences indicative of higher-risk 
plaques in males..$^{38} \mathrm{~A}$ total of 131 ACS individuals (67 males, 64 females) were imaged with a 3.0-T whole-body scanner. By univariate linear regression analysis, male patients had a higher prevalence of thin/ruptured fibrous cap (48\% vs. $17 \%$, for males vs. females, respectively; $\mathrm{OR}, 4.41 ; 95 \% \mathrm{Cl}, 1.97$ to 9.87 ; $P<0.01)$, lipid-rich necrotic core ( $73 \%$ vs. $50 \%$, respectively; $O R, 2.72 ; 95 \% \mathrm{Cl}, 1.31$ to $5.65 ; P=0.01)$ and a higher incidence of intra-plaque hemorrhage (33\% vs. $17 \%$, respectively; $O R$, 2.36; $95 \% \mathrm{Cl}, 1.03$ to $5.38 ; P=0.04)$ compared with females. ${ }^{38} \mathrm{In}$ multivariate logistic regression analysis after adjusting for body mass index, hyperlipidemia, statin use, and angiographic stenosis on MRI, the adjusted OR remained virtually unchanged for the prevalence of thin/ruptured fibrous cap (adjusted OR, 4.41; $95 \% \mathrm{Cl}, 1.97$ to $9.87 ; P<0.01)$ and the presence of a lipid-rich necrotic core (adjusted $\mathrm{OR}, 3.66 ; 95 \% \mathrm{Cl}, 1.67$ to $8.00 ; P=0.01$ ). However, the prevalence of intraplaque hemorrhage was no longer significantly different (adjusted OR, 2.15; 95\% Cl, 0.93 to $4.98 ; P=0.07$ ). ${ }^{38}$ These results support a sex-specific approach for the invasive management of ACS.

An expert committee undersigning a multidisciplinary consensus document recognized that the landmark RCTs have not been powered to assess outcomes specifically for women, because females were largely under-represented in all RCTs. ${ }^{39} \mathrm{~A}$ post hoc subgroup analysis of ACAS showed that the sex differences in CEA outcomes were mainly related to the higher operative stroke/death risk observed in women compared with men (3.6\% vs. $1.7 \%$, respectively), resulting in an inferior RR reduction in the overall benefit gained from CEA over time in females vs males compared with BMT alone (5-year relative RR, 17\% vs. $66 \%$, for females vs. males, respectively). ${ }^{32}$ However, ACAS was performed between 1987 and 1993 and the trial did not have a pre-specified sex subgroup analysis, as was the case with ACST I. ${ }^{29}$ In ACST I, ${ }_{1}^{29}$ the 5 -year benefit gained from CEA in women was half of that achieved in men (absolute RR, $4.08 \%$ vs. $8.21 \%$, respectively). At 10 years, a benefit gained from CEA was only seen in women $<75$ years of age, but it was still inferior to that provided by CEA in asymptomatic men of similar age. ${ }^{40} \mathrm{~A}$ meta-analysis of CAS $^{32}$ and ACST ${ }^{29}$ data showed a significant benefit with surgery compared with BMT for ACS men $(O R, 0.49$; $95 \% \mathrm{Cl}, 0.36$ to 0.66$)$, but not for women $(\mathrm{OR}, 0.96 ; 95 \% \mathrm{Cl}$, 0.63 to 1.45 ; pooled interaction $P=0.01$ ). ${ }^{41}$ A possible reason for the inferior results of CEA/CAS in women compared with men may be the fact that females with ACS often receive suboptimal medical care. ${ }^{42}$

According to the recommendations of the committee participating in the multidisciplinary consensus document, an equipoise between CAS/CEA and modern BMT for ACS is likely, but there is limited evidence to consider BMT alone as the best choice for the management of women with severe ACS (Grade 2, Level of Evidence: B). ${ }^{42}$ A strong recommendation for CEA was provided for women with 60\% to $99 \%$ ACS for reduction of long-term risk of stroke, provided the patient has a 5- to 10year life-expectancy and perioperative stroke/death rates are $\leq 2.0 \%$ (Grade 1, Level of Evidence B). Furthermore, CAS for ACS females should mainly be offered within the context of RCTs including a medical arm with/without a CEA arm. ${ }^{42}$ It was concluded that the overall benefit of carotid revascularization in stroke prevention for women with ACS is expected to be lower than for ACS men (Grade 2, Level of Evidence: B). ${ }^{42}$

\section{Patient adherence with BMT}

Up to $50 \%$ of vascular patients cannot quit smoking. ${ }^{43,44}$ Other patients may discontinue taking their drugs (e.g., statins) because of side-effects or intolerance ${ }^{45,46}$ and older patients may forget to take their medication. A possible pharmacological resistance to clopidogrel or aspirin should also be taken under consideration. ${ }^{47}$ Due to drug resistance/discontinuation or lack of adherence, patients often end up receiving suboptimal BMT and, consequently, inadequate stroke prevention therapy.

As a result of the rigorous surveillance by the investigators in RCTs, patients may be more adherent in RCTs than in clinical practice. Consequently, the results of RCTs may often underestimate or overestimate the benefit of a therapeutic approach. ${ }^{48}$ This discrepancy in the results between RCTs and real-life observational studies/registries should be taken into account when dealing with individual patients. Patients with multiple risk factors may have a higher chance of progression of ACS and may therefore need to be considered for more aggressive treatment strategies, including CEA or CAS.

The outcomes of ACS patients managed with BMT alone and not offered CEA/CAS may be worse in everyday clinical practice compared with those reported in RCTs. A study from Boston, USA. addressed the natural history of patients with moderate (50\% to 69\%) ACS managed with BMT alone and not offered any intervention ( $n=794$ patients; 900 carotid arteries). ${ }^{49}$ Plaque progression occurred in 262 arteries. Of these, 36 patients (13.7\%) developed ipsilateral neurologic symptoms. Of the entire cohort, 90 patients (11.3\%) developed ipsilateral ischemic symptoms despite receiving BMT; $58 \%$ of these were strokes. The 5 -year freedom from symptoms was $88.4 \% \pm 1.5 \%$, while the 5 -year actuarial survival for the entire cohort was $81.9 \% \pm 1.5 \%$, with no advantage seen with BMT. ${ }^{49}$

In the Asymptomatic Carotid Stenosis and Risk of Stroke (ACSRS) study, 1,121 patients with 50\% to 99\% ACS receiving BMT underwent 6-monthly clinical assessment and carotid duplex ultrasound examinations for up to 8 years (mean fol- 
low-up, 4 years). ${ }^{50}$ ACS progression occurred in 222 patients (19.8\%), while 130 first ipsilateral cerebral or retinal ischemic events (59 strokes) were recorded. For patients with 70\% to 99\% ACS at baseline, the 8-year cumulative ipsilateral cerebral ischemic event rate was $12 \%$ in the absence and $21 \%$ in the presence of progression. ${ }^{50}$

A prospective, multicenter $(n=36)$ study from China, the Revascularization of Extracranial Carotid Artery Stenosis (RECAS) trial, demonstrated that ACS patients offered CEA in low-volume centers received suboptimal medical therapy preoperatively compared with high-volume centers, such as aspirin $(73.0 \%$ vs. $88.7 \%$, respectively; $P<0.001)$ and statins $(25.6 \%$ vs. $34.9 \%$, respectively; $P=0.008){ }^{51}$ A similar analysis from the United States using the Vascular Quality Initiative database and including patients undergoing CEA $(n=71,283)$ and CAS $(n=12,053)$ between 2012 and 2017 demonstrated similar results. ${ }^{42}$ Around 10\% to $12 \%$ of patients did not receive an antiplatelet agent preoperatively, whereas approximately $20 \%$ did not receive a statin. ${ }^{42}$ Finally, in a review of data from 3,382 patients admitted to a tertiary referral center with an ischemic stroke, 219 radiographically confirmed strokes adjudicated as carotid-mediated were studied. ${ }^{52}$ On admission, 50\% were receiving antiplatelet therapy and 55\% were receiving lipid-lowering agents, most commonly statins (53\%). A total of 35\% individuals were receiving both an antiplatelet and lipid-lowering medication. ${ }^{52}$ Nearly half (96/219 patients; 43\%) of the (previously asymptomatic) patients presented with an occluded carotid artery as the culprit of their carotid stroke. Based on these results, the authors concluded that BMT alone is unlikely to provide sufficient stroke prevention for all patients with significant $\mathrm{ACS}^{52}$ It was suggested that the stroke risk of individual ACS patients should be stratified and the treatment should be tailored to each patient's needs. ${ }^{53-55}$

\section{Risk prediction tools/improvements in CEA out- comes for ACS patients}

Improvements in MRI/CT imaging techniques and technology nowadays make it possible to identify plaque features associated with increased stroke risk. ${ }^{56,57}$ Irregular plaque morphology and/or ulcerated plaque surface are associated with an increased risk for future stroke. Similarly, the detection of intraplaque hemorrhage is an identifying feature of the vulnerable plaque and is strongly associated with cerebrovascular events. ${ }^{56}$ Intraplaque hemorrhage may be a stronger predictor of stroke risk than clinical risk factors. ${ }^{57}$ Consequently, the use of MRI/CT imaging techniques may help to identify ACS patients at high risk for stroke who would benefit from a prophylactic carotid revascularization procedure. ${ }^{57}$

Besides the improvement in annual stroke rates with BMT alone, ${ }^{4}$ it should be considered that the periprocedural stroke rates associated with CEA for ACS patients have also improved. There are data from some centers where CEA was performed on

Table 2. Predictors/prognostic factors associated with reduced long-term survival in asymptomatic carotid patients undergoing carotid endarterectomy

\begin{tabular}{|c|c|c|c|c|c|c|c|c|c|c|}
\hline Study & Age & CAD & COPD & DM & CKD & $\mathrm{CCO}$ & Smoking & No statin & Low $\mathrm{Hb}$ & Other \\
\hline Kragsterman et al..$^{59}$ (2006) & v & $\mathrm{v}$ & & $\mathrm{v}$ & & & & & & Previous vascular surgery \\
\hline Ballotta et al..$^{60}(2007)$ & & $v$ & & v & & v & & & & \\
\hline Alcocer et al. ${ }^{61}$ (2013) & v & $\mathrm{v}$ & v & v & v & & & & & \\
\hline Conrad et al. ${ }^{62}$ (2013) & v & v & v & v & & & & v & & Neck irradiation \\
\hline Wallaert et al. ${ }^{63}$ (2013) & v & v & v & v & v & v & v & v & & \\
\hline Gupta et al. ${ }^{64}(2013)$ & v & v & v & & & & & & & $\begin{array}{l}\text { PAD, dependent functional } \\
\text { status }\end{array}$ \\
\hline Wallaert et al..$^{65}$ (2016) & v & v & $v$ & v & $v$ & $\mathrm{v}$ & $v$ & $\mathrm{v}$ & & \\
\hline Cooper et al. ${ }^{66}(2016)$ & v & v & v & & & & $v$ & & & \\
\hline DeMartino et al..$^{67}$ (2017) & $v$ & v & $v$ & $\mathrm{v}$ & & v & v & v & v & $\begin{array}{l}\text { Low BMI, prior vascular } \\
\text { surgery, ASA IVN } N \text {, no } \\
\text { aspirin, prior contralateral } \\
\text { CEA }\end{array}$ \\
\hline Morales-Gisbert et al. ${ }^{68}$ (2017) & v & v & v & v & & & & & & \\
\hline Carmo et al. ${ }^{69}$ (2018) & v & v & v & v & $\mathrm{v}$ & & & v & & \\
\hline Keyhani et al..$^{70}$ (2019) & v & v & v & v & v & & & & v & Low BMI, dementia \\
\hline Dasenbrock et al. ${ }^{71}$ (2019) & v & & & v & v & v & & & & ASA IVN \\
\hline
\end{tabular}

$C A D$, coronary artery disease; COPD, chronic obstructive pulmonary disease; DM, diabetes mellitus; CKD, chronic kidney disease \pm dialysis; $C C 0$, contralateral carotid occlusion; Hb, hemoglobin; PAD, peripheral arterial disease; BMI, body mass index; ASA, American Society for Anesthesiology; CEA, carotid endarterectomy. 
ACS patients with death/stroke rates as low as $0.5 \%{ }^{58}$ Therefore, the optimal management of some ACS patients (i.e., BMT alone vs. CEA+BMT) may also be guided by local surgical/medical expertise.

An essential pre-requisite in order to offer a prophylactic carotid intervention to ACS patients is that those individuals should have a reasonable life-expectancy for maximum benefit from the procedure. ${ }^{2}$ Carotid guidelines do not recommend offering an intervention to patients not expected to live long enough to benefit from the procedure. ${ }^{2}$ Various risk prediction models have been developed in an attempt to identify prognostic factors associated with long-term survival in ACS patients undergoing CEA (Table 2) ${ }^{59-71} \mathrm{~A}$ number of negative prognostic factors have been identified, including old age (12 studies), ${ }^{59,61-71}$ cardiac disease (12 studies), ${ }^{59-70}$ diabetes mellitus (11 studies) ${ }_{1}^{59-63,65,67-71}$ chronic obstructive pulmonary disease (10 studies), ${ }_{1}^{61-70}$ chronic kidney disease with/without dialysis (six studies), ${ }_{1}^{61,63,65,69-71}$ statin non-use (five studies), ${ }_{1}^{62,63,65,67,69}$ contralateral carotid occlusion (five studies), ${ }^{60,63,65,67,70}$ and smoking (four studies). ${ }^{63,65-67}$ The simultaneous presence of several of these conditions/criteria in ACS patients should prompt physicians to consider BMT instead of CEA/CAS for the management of these individuals.

\section{Conclusions}

It has been supported that international guidelines are the "Holy Grail" in Medicine. ${ }^{72}$ Such guidelines ensure that the management of patients is uniform and based on Level I Evidence generated by high-quality RCTs. Large, ongoing RCTs, such as the Carotid Revascularization Endarterectomy versus Stenting Trial (CREST)- ${ }^{73}$ and ACST- $2{ }^{74}$ will generate high-quality data and evidence for clinical practice and should be vigorously supported with enrollment of all eligible patients. However, due to local social/cultural population differences and resources in different parts of the world, a "one-size-fits-all" guideline policy may not be appropriate for all patients. ${ }^{72}$ Besides RCTs, future guidelines should also consider evidence from propensity-matched trials (preferably multi-center), audited registries and multi-registry analyses. $^{72}$

Physicians should always seek to optimize patient adherence to BMT according to current guidelines because all-cause and cardiac mortality in ACS are very high. ${ }^{75}$ Nevertheless, some patients may require specific modifications based on individual lifestyle, personal traits, social and cultural characteristics, as well as emerging advances in the field (for example, specific vulnerable carotid plaque features like intraplaque hemorrhage, neovascularization, plaque volume and inflammation that can be detected with the newer imaging approaches). ${ }^{53,76}$ Deciding which is the right treatment for the right patient is crucial. Some patients deserve/require a more aggressive (or a more conservative) approach than others. Consequently, the management of specific ACS patients may need to be individualized, with active patient participation in making health and treatment choices.

\section{Disclosure}

Dr. Gupta reports non-financial support from GE Healthcare and Siemens Medical Solutions USA, Inc. Dr. Mikhailidis has given talks, acted as a consultant or attended conferences sponsored by Amgen, Novo Nordisc, and Libytec. Dr. Katsiki has given talks, attended conferences and participated in trials sponsored by Angelini, Astra Zeneca, Bausch Health, Boehringer Ingelheim, Elpen, Mylan, Novo Nordisk, Sanofi, and Servier. Dr. Chaturvedi is an Associate Editor of Stroke and is on the executive committee of the Carotid Revascularization Endarterectomy versus Stenting Trial (CREST) 2 and the Asymptomatic Carotid Trial (ACT) I. The other authors have no conflicts of interest.

\section{Acknowledgments}

All authors are members of the Faculty Advocating Collaborative and Thoughtful Carotid Artery Treatments (FACTCATS at FACTCATS.org) with the shared goal of optimizing stroke prevention.

\section{References}

1. Virani SS, Alonso A, Benjamin EJ, Bittencourt MS, Callaway CW, Carson AP, et al. Heart disease and stroke statistics: 2020 update: a report from the American Heart Association. Circulation 2020;141:e139-e596.

2. Naylor AR, Ricco JB, de Borst GJ, Debus S, de Haro J, Halliday $A$, et al. Editor's choice: management of atherosclerotic carotid and vertebral artery disease: 2017 clinical practice guidelines of the European Society for Vascular Surgery (ESVS). Eur J Vasc Endovasc Surg 2018;55:3-81.

3. Flaherty ML, Kissela B, Khoury JC, Alwell K, Moomaw CJ, Woo $\mathrm{D}$, et al. Carotid artery stenosis as a cause of stroke. Neuroepidemiology 2013;40:36-41.

4. Keyhani S, Cheng EM, Hoggatt KJ, Austin PC, Madden E, Hebert PL, et al. Comparative effectiveness of carotid endarterectomy vs initial medical therapy in patients with asymptomatic carotid stenosis. JAMA Neurol 2020;77:11101121. 
5. Paraskevas KI, Spence JD, Veith FJ, Nicolaides AN. Identifying which patients with asymptomatic carotid stenosis could benefit from intervention. Stroke 2014;45:3720-3724.

6. Nicolaides AN, Kakkos SK, Kyriacou E, Griffin M, Sabetai M, Thomas DJ, et al. Asymptomatic internal carotid artery stenosis and cerebrovascular risk stratification. J Vasc Surg 2010;52:1486-1496.

7. Kakkos SK, Griffin MB, Nicolaides AN, Kyriacou E, Sabetai MM, Tegos T, et al. The size of juxtaluminal hypoechoic area in ultrasound images of asymptomatic carotid plaques predicts the occurrence of stroke. J Vasc Surg 2013;57:609-618.

8. Stanisić M, Rzepa T. Attitude towards one's illness vs. attitude towards a surgical operation, displayed by patients diagnosed with asymptomatic abdominal aortic aneurysm and asymptomatic internal carotid artery stenosis. Int Angiol 2012;31:376-385.

9. Xu J, Prince AE. Shared decision-making in vascular surgery. J Vasc Surg 2019;70:1711-1715.

10. Jayasooriya GS, Shalhoub J, Thapar A, Davies AH. Patient preference survey in the management of asymptomatic carotid stenosis. J Vasc Surg 2011;53:1466-1472.

11. Oddone EZ, Horner RD, Johnston DC, Stechuchak K, Mcln-

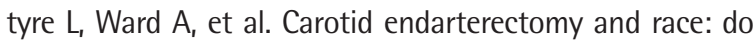
clinical indications and patient preferences account for differences? Stroke 2002;33:2936-2943.

12. Brinjikji W, El-Sayed AM, Kallmes DF, Lanzino G, Cloft HJ. Racial and insurance based disparities in the treatment of carotid artery stenosis: a study of the Nationwide Inpatient Sample. J Neurointerv Surg 2015;7:695-702.

13. Egan BM, Li J, Qanungo S, Wolfman TE. Blood pressure and cholesterol control in hypertensive hypercholesterolemic patients: national health and nutrition examination surveys 1988-2010. Circulation 2013;128:29-41.

14. Zweifler RM, McClure LA, Howard VJ, Cushman M, Hovater $M K$, Safford MM, et al. Racial and geographic differences in prevalence, awareness, treatment and control of dyslipidemia: the reasons for geographic and racial differences in stroke (REGARDS) study. Neuroepidemiology 2011;37:39-44.

15. Gillespie CD, Hurvitz KA; Centers for Disease Control and Prevention (CDC). Prevalence of hypertension and controlled hypertension: United States, 2007-2010. MMWR Supp/ 2013;62:144-148.

16. Halm EA, Tuhrim S, Wang JJ, Rockman C, Riles TS, Chassin MR. Risk factors for perioperative death and stroke after carotid endarterectomy: results of the New York carotid artery surgery study. Stroke 2009;40:221-229.

17. Brown HA, Sullivan MC, Gusberg RG, Dardik A, Sosa JA, Indes JE. Race as a predictor of morbidity, mortality, and neu- rologic events after carotid endarterectomy. J Vasc Surg 2013;57:1325-1330.

18. Dardik A, Bowman HM, Gordon TA, Hsieh G, Perler BA. Impact of race on the outcome of carotid endarterectomy: a population-based analysis of 9,842 recent elective procedures. Ann Surg 2000;232:704-709.

19. Nguyen LL, Henry AJ. Disparities in vascular surgery: is it biology or environment? J Vasc Surg 2010;51(4 Suppl):36S-41S.

20. Chaturvedi S, Madhavan R, Santhakumar S, Mehri-Basha $M$, Raje N. Higher risk factor burden and worse outcomes in urban carotid endarterectomy patients. Stroke 2008;39: 2966-2968.

21. De Rango $P$, Lenti $M$, Simonte $G$, Cieri $E$, Giordano $G$, Caso $V$, et al. No benefit from carotid intervention in fatal stroke prevention for $>80$-year-old patients. Eur J Vasc Endovasc Surg 2012;44:252-259.

22. Rajamani K, Kennedy KF, Ruggiero NJ, Rosenfield K, Spertus J, Chaturvedi S. Outcomes of carotid endarterectomy in the elderly: report from the National Cardiovascular Data Registry. Stroke 2013;44:1172-1174.

23. Wach MM, Dumont TM, Shakir HJ, Snyder KV, Hopkins LN, Levy El, et al. Carotid artery stenting in nonagenarians: are there benefits in surgically treating this high risk population? J Neurointerv Surg 2015;7:182-187.

24. Salomon du Mont $L$, Ravelojaona M, Puyraveau M, Al Sayed M, Ritucci E, Rinckenbach S. Carotid endarterectomy in octogenarian: short- and midterm results. Ann Vasc Surg 2014;28: 917-923.

25. Schmid $S$, Tsantilas $P$, Knappich $C$, Kallmayer $M$, König $T$, Breitkreuz T, et al. Risk of inhospital stroke or death is associated with age but not sex in patients treated with carotid endarterectomy for asymptomatic or symptomatic stenosis in routine practice: secondary data analysis of the nationwide german statutory quality assurance database from 2009 to 2014. J Am Heart Assoc 2017;6:e004764.

26. Hobbs LK, Ramdon A, Roddy SP, Hnath JC, Yeh CC, Darling $\mathrm{RC}$ 3rd. Outcomes for carotid endarterectomy in nonagenarians. J Vasc Surg 2020;71:96-103.

27. Rinckenbach V, Rinckenbach $S$, Thaveau F, Hassani O, Hedelin G, Chakfé N, et al. Mortality and morbidity of consecutive surgical carotid revascularisations in octogenarians. $J$ Mal Vasc 2007;32:192-200.

28. Naylor AR. Time to rethink management strategies in asymptomatic carotid artery disease. Nat Rev Cardiol 2011;9:116124.

29. Halliday A, Mansfield A, Marro J, Peto C, Peto R, Potter J, et al. Prevention of disabling and fatal strokes by successful carotid endarterectomy in patients without recent neuro- 
logical symptoms: randomised controlled trial. Lancet 2004;363:1491-1502.

30. Melin AA, Schmid KK, Lynch TG, Pipinos II, Kappes S, Longo $\mathrm{GM}$, et al. Preoperative frailty Risk Analysis Index to stratify patients undergoing carotid endarterectomy. J Vasc Surg 2015;61:683-689.

31. Pandit V, Lee A, Zeeshan M, Goshima K, Tan TW, Jhajj S, et al. Effect of frailty syndrome on the outcomes of patients with carotid stenosis. J Vasc Surg 2020;71:1595-1600.

32. Executive Committee for the Asymptomatic Carotid Atherosclerosis Study. Endarterectomy for asymptomatic carotid artery stenosis. JAMA 1995;273:1421-1428.

33. Jalbert JJ, Nguyen LL, Gerhard-Herman MD, Jaff MR, White $\mathrm{CJ}$, Rothman AT, et al. Outcomes after carotid artery stenting in medicare beneficiaries, 2005 to 2009. JAMA Neurol 2015;72:276-286.

34. Rothwell PM, Goldstein LB. Carotid endarterectomy for asymptomatic carotid stenosis: asymptomatic carotid surgery trial. Stroke 2004;35:2425-2427.

35. Madsen $T E_{1}$ Khoury J, Alwell $K_{1}$ Moomaw CJ, Rademacher $E_{1}$ Flaherty $M L$, et al. Sex-specific stroke incidence over time in the Greater Cincinnati/Northern Kentucky Stroke Study. Neurology 2017;89:990-996.

36. Hellings WE, Pasterkamp G, Verhoeven BA, De Kleijn DP, De Vries JP, Seldenrijk KA, et al. Gender-associated differences in plaque phenotype of patients undergoing carotid endarterectomy. J Vasc Surg 2007;45:289-297.

37. Phan HT, Reeves MJ, Blizzard CL, Thrift AG, Cadilhac DA, Sturm J, et al. Sex differences in severity of stroke in the INSTRUCT study: a meta-analysis of individual participant data. J Am Heart Assoc 2019;8:e010235.

38. Ota H, Reeves MJ, Zhu DC, Majid A, Collar A, Yuan C, et al. Sex differences in patients with asymptomatic carotid atherosclerotic plaque: in vivo 3.0-T magnetic resonance study. Stroke 2010;41:1630-1635.

39. De Rango P, Brown MM, Leys D, Howard VJ, Moore WS, Paciaroni $\mathrm{M}$, et al. Management of carotid stenosis in women: consensus document. Neurology 2013;80:2258-2268.

40. Halliday A, Harrison M, Hayter E, Kong X, Mansfield A, Marro J, et al. 10-Year stroke prevention after successful carotid endarterectomy for asymptomatic stenosis (ACST-1): a multicentre randomised trial. Lancet 2010;376:1074-1084.

41. Rothwell PM. ACST: which subgroups will benefit most from carotid endarterectomy? Lancet 2004;364:1122-1123.

42. Dansey KD, Pothof AB, Zettervall SL, Swerdlow NJ, Liang P, Schneider JR, et al. Clinical impact of sex on carotid revascularization. J Vasc Surg 2020;71:1587-1594.

43. Almaaitah S, Ciemins EL, Joshi V, Arora A, Meskow C, Roth- berg MB. Variation in patient smoking cessation rates among health-care providers: an observational study. Chest 2020;158:2038-2046.

44. McHugh SM, Eisenberg N, Montbriand J, Roche-Nagle G. Smoking cessation rates among patients undergoing vascular surgery in a Canadian center. Ann Vasc Surg 2017;45:138143.

45. Banach M, Mikhailidis DP. Statin intolerance: some practical hints. Cardiol Clin 2018;36:225-231.

46. Paraskevas $\mathrm{KI}$, Mikhailidis DP, Veith FJ. Optimal statin type and dosage for vascular patients. J Vasc Surg 2011;53:837844.

47. Alakbarzade $V$, Huang $X$, Ster IC, McEntagart M, Pereira AC. High on-clopidogrel platelet reactivity in ischaemic stroke or transient ischaemic attack: systematic review and meta-analysis. J Stroke Cerebrovasc Dis 2020;29:104877.

48. Paraskevas $\mathrm{Kl}$, de Borst GJ, Veith FJ. Why randomized controlled trials do not always reflect reality. J Vasc Surg 2019; 70:607-614.

49. Conrad MF, Boulom V, Mukhopadhyay S, Garg A, Patel VI, Cambria RP. Progression of asymptomatic carotid stenosis despite optimal medical therapy. J Vasc Surg 2013;58:128135.

50. Kakkos SK, Nicolaides AN, Charalambous I, Thomas D, Giannopoulos A, Naylor AR, et al. Predictors and clinical significance of progression or regression of asymptomatic carotid stenosis. J Vasc Surg 2014;59:956-967.

51. Yang $B$, Ma $Y$, Wang $T$, Chen $Y$, Wang $Y$, Zhao Z, et al. Carotid endarterectomy and stenting in a Chinese population: safety outcome of the revascularization of extracranial carotid artery stenosis trial. Trans/ Stroke Res 2021;12:239-247.

52. Klarin D, Cambria RP, Ergul EA, Silverman SB, Patel VI, LaMuraglia GM, et al. Risk factor profile and anatomic features of previously asymptomatic patients presenting with carotid-related stroke. J Vasc Surg 2018;68:1390-1395.

53. Saba L, Moody AR, Saam T, Kooi ME, Wasserman BA, Staub $D$, et al. Vessel wall-imaging biomarkers of carotid plaque vulnerability in stroke prevention trials: a viewpoint from the Carotid Imaging Consensus Group. JACC Cardiovasc Imaging 2020;13:2445-2456.

54. Lanza G, Setacci C, Ricci S, Castelli P, Cremonesi A, Lanza J, et al. An update of the Italian Stroke Organization: Stroke Prevention Awareness Diffusion Group guidelines on carotid endarterectomy and stenting: a personalized medicine approach. Int J Stroke 2017;12:560-567.

55. Lanza G, Giannandrea D, Lanza J, Ricci S, Gensini GF. Personalized-medicine on carotid endarterectomy and stenting. Ann Transl Med 2020;8:1274. 
56. Saba L, Yuan C, Hatsukami TS, Balu N, Qiao Y, DeMarco JK, et al. Carotid artery wall imaging: perspective and guidelines from the ASNR vessel wall imaging study group and expert consensus recommendations of the American Society of Neuroradiology. AJNR Am J Neuroradiol 2018;39:E9-E31.

57. Schindler A, Schinner R, Altaf N, Hosseini AA, Simpson RJ, Esposito-Bauer $\mathrm{L}$, et al. Prediction of stroke risk by detection of hemorrhage in carotid plaques: meta-analysis of individual patient data. JACC Cardiovasc Imaging 2020;13(2 Pt 1):395-406

58. Vikatmaa P, Mitchell D, Jensen LP, Beiles B, Björck M, Hal-

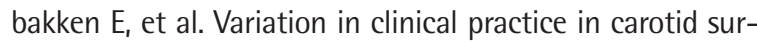
gery in nine countries 2005-2010: lessons from VASCUNET and recommendations for the future of national clinical audit. Eur J Vasc Endovasc Surg 2012;44:11-17.

59. Kragsterman B, Björck $M$, Lindbäck J, Bergqvist D, Pärsson $\mathrm{H}$; Swedish Vascular Registry (Swedvasc). Long-term survival after carotid endarterectomy for asymptomatic stenosis. Stroke 2006;37:2886-2891.

60. Ballotta E, Meneghetti G, Manara R, Baracchini C. Longterm survival and stroke-free survival after eversion carotid endarterectomy for asymptomatic severe carotid stenosis. $J$ Vasc Surg 2007;46:265-270.

61. Alcocer F, Mujib M, Lowman B, Patterson MA, Passman MA, Matthews TC, et al. Risk scoring system to predict 3-year survival in patients treated for asymptomatic carotid stenosis. J Vasc Surg 2013;57:1576-1580.

62. Conrad MF, Kang J, Mukhopadhyay S, Patel VI, LaMuraglia GM, Cambria RP. A risk prediction model for determining appropriateness of CEA in patients with asymptomatic carotid artery stenosis. Ann Surg 2013;258:534-540.

63. Wallaert JB, Cronenwett JL, Bertges DJ, Schanzer A, Nolan BW, De Martino R, et al. Optimal selection of asymptomatic patients for carotid endarterectomy based on predicted 5-year survival. J Vasc Surg 2013;58:112-118.

64. Gupta PK, Ramanan B, Mactaggart JN, Sundaram A, Fang X, Gupta $H$, et al. Risk index for predicting perioperative stroke, myocardial infarction, or death risk in asymptomatic patients undergoing carotid endarterectomy. J Vasc Surg 2013;57:318-326.

65. Wallaert JB, Newhall KA, Suckow BD, Brooke BS, Zhang M,

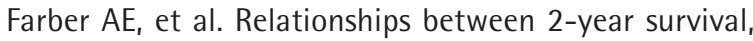
costs, and outcomes following carotid endarterectomy in asymptomatic patients in the Vascular Quality Initiative. Ann Vasc Surg 2016;35:174-182.
66. Cooper M, Arhuidese IJ, Obeid T, Hicks CW, Canner J, Malas MB. Perioperative and long-term outcomes after carotid endarterectomy in hemodialysis patients. JAMA Surg 2016;151:947-952.

67. DeMartino RR, Brooke BS, Neal D, Beck AW, Conrad MF, Arya $\mathrm{S}$, et al. Development of a validated model to predict 30-day stroke and 1-year survival after carotid endarterectomy for asymptomatic stenosis using the Vascular Quality Initiative. J Vasc Surg 2017;66:433-444.

68. Morales-Gisbert SM, Zaragozá García JM, Plaza Martínez Á, Gómez Palonés FJ, Ortiz-Monzón E. Development of an individualized scoring system to predict mid-term survival after carotid endarterectomy. J Cardiovasc Surg (Torino) 2017; 58:535-542

69. Carmo M, Barbetta I, Bissacco D, Trimarchi S, Catanese V, Bonzini $M$, et al. Development and validation of a score to predict life expectancy after carotid endarterectomy in asymptomatic patients. J Vasc Surg 2018;67:175-182.

70. Keyhani S, Madden E, Cheng EM, Bravata DM, Halm E, Aus-

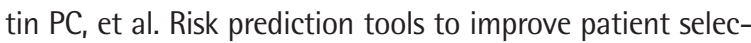
tion for carotid endarterectomy among patients with asymptomatic carotid stenosis. JAMA Surg 2019;154:336-344.

71. Dasenbrock HH, Smith TR, Gormley WB, Castlen JP, Patel NJ, Frerichs KU, et al. Predictive score of adverse events after carotid endarterectomy: the NSOIP Registry Carotid Endarterectomy Scale. J Am Heart Assoc 2019;8:e013412.

72. Veith FJ, Bell PR. How many of you can read but still not see? A comment on a recent review of carotid guidelines. Eur J Vasc Endovasc Surg 2016;51:471-472.

73. Howard VJ, Meschia JF, Lal BK, Turan TN, Roubin GS, Brown $\mathrm{RD} \mathrm{Jr}$, et al. Carotid revascularization and medical management for asymptomatic carotid stenosis: protocol of the CREST-2 clinical trials. Int J Stroke 2017;12:770-778.

74. Bulbulia R, Halliday A. The Asymptomatic Carotid Surgery Trial-2 (ACST-2): an ongoing randomised controlled trial comparing carotid endarterectomy with carotid artery stenting to prevent stroke. Health Technol Assess 2017;21:1-40.

75. Giannopoulos A, Kakkos S, Abbott A, Naylor AR, Richards T, Mikhailidis DP, et al. Long-term mortality in patients with asymptomatic carotid stenosis: implications for statin therapy. Eur J Vasc Endovasc Surg 2015;50:573-582.

76. Saba L, Saam T, Jäger HR, Yuan C, Hatsukami TS, Saloner D, et al. Imaging biomarkers of vulnerable carotid plaques for stroke risk prediction and their potential clinical implications. Lancet Neurol 2019;18:559-572. 